\title{
Notes on the Southernmost Distributional Record for the Yellow-spotted Wolfsnake, Lycodon cf. flavomaculatus (Wall 1907), from Tamil Nadu, India
}

\author{
Surya Narayanan ${ }^{1}$, Naveen Joseph ${ }^{2}$, Melvin Selvan ${ }^{3}$, and Ahmed Jerith ${ }^{2}$ \\ ${ }^{1}$ Wayanad Wild, Lakkidi, Vythiri, Kerala, India (surya.ornata@gmail.com) \\ ${ }^{2}$ National Troopers for Conservation of Nature, Palayamkottai, Tirunelveli, Tamil Nadu, India \\ ${ }^{3}$ Valanesam Road, Gundupatti, Kodaikanal, Tamil Nadu, India
}

$T^{1}$ he Yellow-spotted Wolfsnake (Lycodon flavomaculatus) is one of seven congeners known to occur in mainland India (Uetz et al. 2016). Boulenger (1893) considered this species to be a color variant of the Indian Wolfsnake (Lycodon aulicus), but Wall (1907) recognized it as a distinct species after examining the specimen collected at the type locality in Dharwad, Karnataka. He also examined five other specimens, of which four were from Sangli, Kirkee (Khadki), Poona (Pune), and Nashik in Maharashtra and one was from Faizabad in Uttar Pradesh; however, the latter was considered invalid by Wallach et al. (2014). The presence of this species in various other parts of India has been subsequently documented. Sharma et al. (2015), in a detailed discussion of locality records, supported the validity of localities at Mandla and Balaghat by providing a new record from Vidisha in Madhya Pradesh, but raised doubts about a record from Chattisgarh (Srinivasalu et al. 2014). Murthy (1991) listed a record in Tamil Nadu from the Nilgiri Biosphere Reserve, but Mukherjee and Bhupathy (2007) demonstrated that the specimen was a Yellow-collared Wolfsnake (L. flavicollis). However, Melvinselvan [sic] et al. (2016) recently documented the presence of L. flavomaculatus in Tamil Nadu. Herein we provide another, even more southerly record from Tamil Nadu of an individual tentatively assigned to the same species.

At 2130 h on 15 February 2015, we found a snake (Fig. 1) that looked like a L. flavomaculatus in an agricultural plot near Nagalapuram in Tuticorin District $\left(9.206138^{\circ}\right.$, $78.195638^{\circ}$ ). We collected morphological and meristic data and, using a Canon Eos 600D camera, took voucher photographs for further comparisons. We counted dorsal scale rows one head length behind the neck, at approximately midbody, and one head length in front of the cloacal plate, and ventral scales per Dowling (1951) before releasing the snake at the original site of capture.
Morphology and color pattern of the snake matched characteristics of L. flavomaculatus (Smith 1943; Captain 1999; Whitaker and Captain 2004; Table 1). Our snake had nine supralabials, whereas the Northern Wolfsnake (L. striatus) has eight supralabials. Although Wall (1907) distinguished L. flavomaculatus and L. striatus based on a single supralabial touching the nasal in L. flavomaculatus (first two supralabials touch the nasal in L. striatus), Captain (1999) considered this an unstable taxonomic character inadequate for diagnosing the two species. Both of the individuals we examined (our snake and that recorded by Melvinselvan [sic] et al. 2016) have only the first supralabial in contact with the nasal.

Nagalapuram is in southern Tamil Nadu (Fig. 2) at an elevation of about $100 \mathrm{~m}$ and about $55 \mathrm{~km}$ south of the previously recorded southernmost locality (Melvinselvan [sic] et al. 2016). The new site is in the rainshadow on the eastern slopes of the Western Ghats and receives an annual rainfall of about $700 \mathrm{~mm}$. The natural habitat in the area, dry grassland with scattered small boulders, has been largely replaced by stands

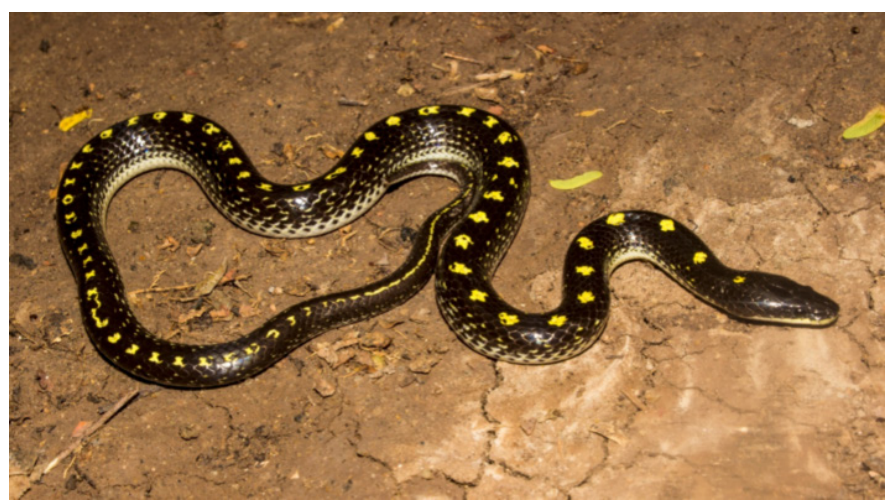

Fig. 1. Dorsal view of an individual tentatively identified as a Yellowspotted Wolfsnake (Lycodon cf. flavomaculatus) from Nagalapuram, Tamil Nadu. Photograph by Naveen Joseph. 
Table 1. Meristic and morphological data for Yellow-spotted Wolfsnakes (Lycodon flavomaculatus) listed by Captain (1999) and the individuals described in Melvinselvan [sic] et al. (2016) and herein.

\begin{tabular}{lccc} 
Character & Captain (1999) & Melvinselvan [sic] et al. (2016) & This work \\
\hline Dorsal scale rows & $17: 17: 15$ & $17: 17: 15$ & $17: 17: 15$ \\
\hline Ventrals & 165 & 173 & 161 \\
\hline Subcaudals & 61 & NA & $42+$ (tail broken) \\
\hline Supralabials (touching eyes) & $9(3-5)$ & 1 & $9(3-5)$ \\
\hline Supralabials in contact with nasal & 1 & 10 & 1 \\
\hline Infralabials & 10 & 1 & 10 \\
\hline Loreals & 1 & 1 & 1 \\
\hline Preoculars & 1 & 2 & 1 \\
\hline Postoculars & 2 & $2+3$ & $2+3$ \\
\hline Temporals & $2+3$ & 192 & 375 \\
\hline SVL $(\mathrm{mm})$ & 345 & $\mathrm{NA}$ & $80+$ (tail broken)
\end{tabular}

of Mesquite (Prosopis juliflora) and agriculture. Sharma et al. (2015) noted that L. flavomaculatus occurred in diverse habitats ranging from dry grasslands to dry deciduous forests and in areas that differ in annual rainfall from low (in most parts of the range) to high on parts of the Deccan Plateau (which composes much of peninsular India).

The Yellow-spotted Wolfsnake (L. flavomaculatus) was considered endemic to western and central India by Captain (1999) and Whitaker and Captain (2004), but our record and one earlier report (Melvinselvan [sic] et al. 2016) appear to demonstrate the presence of the species in Tamil Nadu. However, in the absence of molecular support and considering the apparent gap in the distribution between these new locations and the nearest previously known locality in Dharwad, we conservatively refer this individual to $L$. cf. flavomaculatus. We believe these snakes are likely to occur in a wider geographic area where habitats such as the dry grasslands and dry deciduous forests on the eastern slopes of the Western Ghats appear to be suitable.

\section{Acknowledgements}

We thank Deepak Veerapan for his suggestion regarding the identity of the species and for valuable comments on an earlier draft of this manuscript. We also thank Abhishek Samrat for providing the map (Fig. 2).

\section{Literature Cited}

Boulenger, G.A. 1893. Catalogue of the Snakes in the British Museum (Natural History). Volume I., containing the Families Typhlopia, Glaudoniida, Boida, Ilysiida, Uropeltida, Xenopeltida, and Colubrida aglypha, part. Trustees of the British Museum (Natural History), London.

Captain, A. 1999. On the identification of Lycodon flavomaculatus Wall 1907. Journal of the Bombay Natural History Society 96: 323-327.

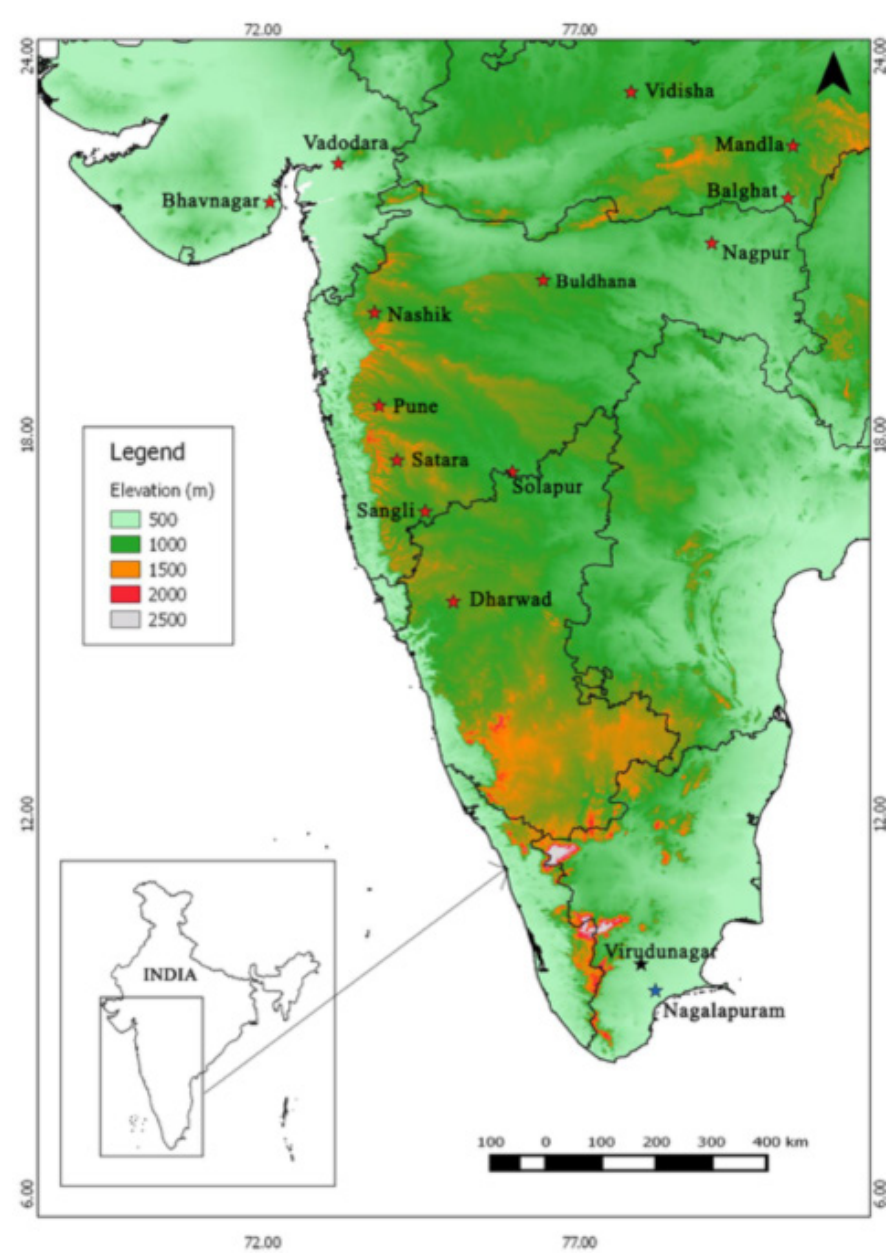

Fig. 2. Distribution of the Yellow-spotted Wolfsnake (Lycodon flavomaculatus) in mainland India. Previously known localities are marked by red stars, the locality reported by Melvinselvan [sic] et al. (2016) is marked with a black star, and the new locality reported herein is marked with a blue star. 
Dowling, H.G. 1951. A proposed standard system of counting ventrals in snakes. British Journal of Herpetology 1: 97-99.

Melvinselvan [sic], G., R.S. Narayanan, and V. Sharma. 2016. Geographic distribution: Lycodon flavomaculatus (Yellow-spotted Wolf Snake). Herpetological Review 47: 427.

Mukherjee, D. and S. Bhupathy. 2007. A new species of Wolf Snake (Serpentes: Colubridae: Lycodon) from Anaikatti Hills, Western Ghats, Tamil Nadu, India. Russian Journal of Herpetology 14: 21-26.

Murthy, T.S.N. 1991. A rare Wolf Snake, Lycodon flavomaculatus, from the Nilgiri Biosphere Reserve, South India. The Snake 23: 104-106.

Sharma, V., A. Jain, and R. Bhandari. 2015. A new locality for the elusive and endemic Yellow-Spotted Wolf Snake (Lycodon flavomaculatus Wall 1907), with notes on distribution and habitat. Reptiles \& Amphibians 22: 164-167.

Smith, M.A. 1943. The Fauna of British India, Ceylon and Burma, including the
Whole of the Indo-Chinese Sub-region. Reptilia and Amphibia. Vol. IIISerpentes. Taylor \& Francis, London

Srinivasulu, C., B. Srinivasulu, and S. Molur 2014. The Status and Distribution of Reptiles in the Western Ghats, India. Conservation Assessment and Management Plan (CAMP). Wildlife Information Liaison Development Society, Coimbatore, Tamil Nadu. India.

Uetz, P., P. Freed, and J. Hošek (eds.). 2016. The Reptile Database (http://www. reptile-database.org/).

Wall, F. 1907. Some new Asian snakes. Journal of the Bombay Natural History Society 17: 612-618.

Wallach, V., K.L. Williams, and J. Boundy. 2014. Snakes of the World: A Catalogue of Living and Extinct Species. CRC Press, Boca Raton, Florida.

Whitaker, R. and A. Captain. 2004. Snakes of India. The Field Guide. Draco Books, Chennai, India. 